\title{
Developing and Using a Rubric to Provide Feedback and Improve CSD Clinical Writing
}

\author{
Laura B. Willis \\ Auburn University, lbg0003@auburn.edu \\ Lindsey Piazza \\ Auburn University, ivylind@auburn.edu \\ DOI: https://doi.org/10.30707/TLCSD3.2Willis
}

Follow this and additional works at: https://ir.library.illinoisstate.edu/tlcsd

Part of the Scholarship of Teaching and Learning Commons

\section{Recommended Citation}

Willis, Laura B. and Piazza, Lindsey (2019) "Developing and Using a Rubric to Provide Feedback and Improve CSD Clinical Writing," Teaching and Learning in Communication Sciences \& Disorders: Vol. 3: Iss. 2 , Article 4.

DOI: https://doi.org/10.30707/TLCSD3.2Willis

Available at: https://ir.library.illinoisstate.edu/tlcsd/vol3/iss2/4

This Reflection on SoTL is brought to you for free and open access by ISU ReD: Research and eData. It has been accepted for inclusion in Teaching and Learning in Communication Sciences \& Disorders by an authorized editor of ISU ReD: Research and eData. For more information, please contact ISUReD@ilstu.edu. 


\title{
Developing and Using a Rubric to Provide Feedback and Improve CSD Clinical Writing
}

\begin{abstract}
The benefits of rubrics have long been established and their use encouraged in various fields of study. The authors sought to create a rubric specific to the needs in CSD to more clearly share expectations for student clinical writing and more comprehensively assess the quality of their writing. The faculty collaborated with the Office of Academic Assessment to develop a rubric to address these issues. The rubric was developed using VALUE rubrics as guidance, as well as the unique requirements for Communication Sciences and Disorders documentation. This specific rubric may be used to grade and provide feedback to improve the comprehension of the many facets of superior clinical writing, provide transparency in grading, and to improve the quality of future documentation. In addition, it provides the professor a framework from which to teach expectations of the document and descriptions of student performance to increase proficiency and effectiveness in grading. It may be used for undergraduate and graduate students in both academic and clinical courses.
\end{abstract}

\section{Keywords}

Writing, Assessment, Pedagogy, Rubric

\section{Cover Page Footnote}

Portions of this manuscript have been accepted for a poster presentation at the 2018 Annual Convention of the American Speech-Language-Hearing Association. 
Higher education in Communication Sciences and Disorders (CSD) maintains rigorous standards in curriculum, including written language skills. However, educators have noted difficulties with teaching students the best methods for clinical documentation. Strong writing is critical for speechlanguage pathologists, and the undergraduate curriculum should include writing instruction (Plante, 2011). Anecdotally, professors may comment that student writing skills have deteriorated over the years, and even the United States Department of Education (2006) has reported concerns about the declining quality of student learning for writing skills (as cited in Plante, 2011). Standard $\mathrm{V}-\mathrm{A}$ and $\mathrm{B}$ of The American Speech-Language-Hearing Association (ASHA) standards for certification include the ability to write and comprehend a variety of reports and treatment plans, as well as interpret, integrate, and synthesize information for intervention purposes (ASHA, 2014). The knowledge of professional writing gained as an undergraduate student lays the foundation for the rigors of writing in graduate school and it may be the only instruction if the student becomes a speech-language pathology assistant (SLPA). Therefore, significant thought should be given to the method of grading and instructor feedback to develop these skills.

The authors teach required academic courses for senior undergraduate students: the first course focusing on short-term documentation (SOAP/Progress Notes), and the second focusing on longterm documentation. Significant time is devoted to instruction of content for these pieces of documentation, as well as guidelines for writing professionally. This is the first exposure the students have within their course sequence to learn and practice professional writing and it can be an arduous process. Both course professors utilize the writing instruction principles of Butler and Silliman (2002): models, writing practice, explicit instruction and feedback. Before students are expected to generate high quality documentation, explicit instruction within a lecture format is provided regarding the required content, form, and style of the reports. Embedded within the instruction is the provision of written models to underscore what composes a superior report when compared to a report lower in quality. Following instruction and examples, students are asked to generate sample reports as a class, in a small group, and, ultimately as an individual. Feedback is provided to the students by their peers during peer response workshops and by the instructor following the final submission. Additionally, the instructor is available for feedback during office hours and via email. As part of the [University] undergraduate curriculum, students in both of these courses are assigned to a client in the university clinic that they observe on a weekly basis. The students are not responsible for providing skilled therapy services but are in the therapy room with their assigned client to observe and assist the graduate clinician as necessary. It is this client's data and goals which are used in the clinical documentation. The assignments provide the student with "real-life" experience using actual client data but no protected health information (PHI) is included.

\section{INTRODUCTORY/FIRST COURSE IN THE SEQUENCE}

It is the goal that by completing the first course, the student will exhibit emerging skills in how to use professional language and tone and be able to state the components of short-term documentation as required by third-party payers. Explicit instruction is also given regarding grammatical rules, audience, professional language, tone, and common errors in writing. Students are educated in basic principles of these areas and why these areas are important to consider when writing. The following "Common Errors" listed in Table 1 from a text by Burrus and Willis (2017) text are used as a guide for a portion of this discussion. 
Table 1

Common Errors

Spelling and typographical errors

Wordiness

Ambiguity

Wrong use of abbreviations

Not separating fact from opinion

Redundancy

Lack of professional terminology

Lack of organization and sequence

Tense errors

Lack of objectivity

Use of contractions and informal language

Following class discussion, the students are provided with samples and asked to identify errors and modify the sample to improve the quality of the writing. After this level of instruction, the class watches a brief video of a client and composes a progress note in the SOAP format as a group. Finally, students complete a progress note with their client's data prior to a peer response workshop. Students are asked to complete a self-evaluation form prior to participating in the workshop which guides them to consider the many facets of a progress note and to identify in which areas they feel confident or confused. During the workshop, the students complete a peer review of two different classmates' work. The students are verbally instructed regarding principles that result in a constructive review and are provided with written guidelines. The professor for this course worked with the University Writing Center to develop these instructions which include advice to read the report multiple times for the distinct expectations of the document (grammar, content, and analysis), as well as ensuring all the required components are included using sufficient detail (subjective, objective, assessment, plan). The students are asked to consider the diverse audience and focus on clarity, completeness, and professional writing. It is encouraged to use the rubric when communicating feedback. The forms are completed during class time (50-60 minutes) and once the review forms are completed, discussion time among the student pairs is encouraged to solicit additional feedback. During the semester, there are two progress note assignments.

\section{SECOND COURSE IN THE SEQUENCE}

The students take the second course during the following semester and the focus shifts to the ability to interpret and analyze important information across clinical sessions and in research articles. Students are given two primary assignments, the semester report and PICO assignment. The semester report (long-term documentation) allows students to reflect on a client's performance during the semester. This assignment provides the opportunity to learn how to summarize and analyze the client's performance with regard to progress toward goals, cues, materials, reinforcement, and evidence-based practice (EBP). After students are educated regarding the required content of the semester report and shown numerous examples, they are assigned a hypothetical case to complete in small groups. Following the group exercise, the students are required to turn in a Semester Report using the data from their own client.

The PICO assignment allows students to frame a clinical question, find evidence, assess evidence and make a clinical decision regarding treatment methods for a given client. For this assignment, 
students are assigned a hypothetical client (age, gender and diagnosis) and asked to frame a PICO question in order to choose the best EBP for treatment. The students must choose two different evidence-based methods appropriate for the client and use research articles to support the particular technique they recommend. In class, the instructor provides examples of evidence-based and nonevidence based practice and class discussion is encouraged. The students are exposed to several completed PICO reports, and criteria requirements for a complete analysis of each intervention method with EBP are highlighted. In addition, students are given class time at the library guided by a discipline-specific librarian to locate articles that support evidence-based practice for their hypothetical client. Finally, they are required to turn in a complete PICO report to the professor.

\section{RATIONALE}

The authors have used various grading formats for writing but were not satisfied with how the grades reflected the quality of the work. In the most recent grading scale, points were awarded based on the presence or absence of information. For example, if a student included any description of the client in the Subjective/S portion of the SOAP note, the student earned all possible points. Therefore, if the content of the assignment was addressed (i.e., for the Progress note; Subjective, Objective, Assessment, Plan), the student who displayed a higher level of analysis and more mature tone and language was earning a very similar score to the student who did not. A small number of points were used to assess professional language, tone, grammar and spelling but overall this minimally influenced the grade. The authors felt strongly that this method did not adequately assess the piece of documentation since a report can include all the required elements but not be written professionally. We wished to increase the specificity of our grading and feedback to better assess more sophisticated writing skills. If we could provide more detailed feedback while using an objective tool, we could enrich our writing instruction by making expectations clearer and thereby increase the quality of the student's future writing.

\section{THE BENEFITS AND USE OF RUBRICS}

A rubric may be defined as "a coherent set of criteria for student's work that includes descriptions of levels of performance quality on the criteria" (Brookhart, 2013, p. 2). The primary purpose of rubrics is that they evaluate performance. Those that are valuable have criteria that are fitting and descriptions that are well-written (Brookhart, 2013). Since the student's work can be matched with a description of performance, it is effective for showing the current level and the desired level for the next assignment. Rubrics benefit instructors by allowing them to create assignments that encourage students to display the exact targets and tailor instructions to meet the students' needs (Allen, 2014).

Providing a rubric when explaining a writing assignment is useful so that it will delineate the learning target, serve as a guide to help the student plan and monitor their work, and teach the student what the desired performance is for the assignment (Brookhart, 2013). A score or numerical value provided by a professor does not clearly indicate how a student can improve their performance. However, descriptions provided by rubrics assist the student in understanding why they earned a specific score (Moskal, 2000). Additionally, if used formatively, the student's performance as described by ratings on a rubric can be used to identify the next steps of how to 
improve writing for the next document (Brookhart, 2013). Providing students with a grading rubric that includes expectations of content and form refutes the misconception among students that the grading of writing is subjective, communicates what the student should be focusing on, and minimizes "negotiations" regarding grading (Plante, 2011).

Although rubrics are routinely used to evaluate writing samples, the current literature review yielded no publications discussing the use of rubrics to grade clinical writing assignments in undergraduate Communication Sciences and Disorders (CSD) academic courses (Moskal, 2000). Although the authors have yet to collect data, it was felt that other CSD professors would appreciate our rubric as a guide for grading their students' written documentation or adapting for their purposes. The clinical writing rubric published by Schneider-Cline (2017) aligns most closely with our rubric and uses a checklist with multiple items under the categories of use, form, and content. Each category is assigned a ranking ranging from 1 (not met) to 5 (consistently met). This rubric was used within a voluntary clinical writing workshop for graduate students and was used to measure changes in writing skill, but results were not provided to students. Grillo, Koenig, Gunter, and Kim (2014) provided two module-specific coding rubrics in their study to determine effective teaching modules to improve critical thinking, evidence-based practice and professional writing in CSD. One rubric assessed the microstructure, macrostructure and transitions within the assessed written reports and points allotted in each category for the presence of six particular criteria. The second rubric was very similar in how the points are allotted, however it focuses on more specific content of EBP. Both rubrics were used to determine which teaching module improved student progress. While they cannot be directly compared to the present rubric to assess clinical writing, within the field of CSD, Plante (2011) provides a "Base Writing Rubric" for assessing papers and Lee-Wilkerson and Chabon (2008) provide a rubric used for reflection journals. Plante (2011) provided limited explanation of the Base Rubric; however, it does reflect the first level of writing instruction through teaching and grading the macrostructure. The reflection rubric was used to demonstrate ways reflections could be written, provide components that were expected to occur, and to indicate the specific learner outcome. Students were required to write a reflection about a learning experience in order to address one or more learner outcomes. Lee-Wilkerson and Chabon (2008) reported that the use of a rubric enabled them to improve the assessment process and provided valuable information regarding what was learned, how it was learned, and what additional learning was needed.

\section{DEVELOPMENT PROCESS}

The University Writing Center hosts frequent classes to provide instruction for professors regarding methods to increase the quality of student writing assignments. Through this avenue, one of the authors was exposed to the use of rubrics for grading student writing. The authors sought the guidance of the Office of Academic Assessment to create a rubric specific for the unique demands of clinical writing in CSD. In the introductory meeting, the following primary questions were discussed: What is important in writing CSD documents? How can students clearly understand expectations and the teacher fairly assess the quality of the writing? Katie Boyd, Associate Director of the Office of Academic Assessment, provided examples of VALUE (Valid Assessment of Learning in Undergraduate Education) rubrics used by other professors at our university and others from the Association of American Colleges and Universities (Association of American Colleges and Universities, 2017). The 16 VALUE rubrics were developed nationally by 
teams of faculty across disciplines and are published online by the American Colleges and Universities (Finley, 2011). After learning about the field of CSD and what we felt was important in assessment of writing, Ms. Boyd suggested we review the following rubrics to use as resources in developing one specific to our needs: Inquiry and Analysis Value Rubric, Written Communication Value Rubric, and Critical Thinking Value Rubric. We reviewed all 16 rubrics and agreed that these were most representative of what we felt to be most crucial to generate high quality CSD documentation. Since the VALUE rubrics are general and not specific to CSD or clinical writing, the behavioral anchors of the rubric areas needed to be modified to reflect what is relevant for CSD documentation. Based on our assessment needs, we chose the following categories from the rubrics since they represented what we believed to be most critical: content development, analysis, use of professional language, and control of syntax and mechanics. We modified the general language of these behavioral anchors and tailored them to specifically address CSD documentation.

Moskal (2000) states that when creating a rubric, the top level of performance should be described first and then the lowest level of performance. We followed this recommendation and then filled in the remaining two descriptions. The rating scale range is as follows: 1/beginning, 2/developing, $3 /$ mature, and 4/exemplary. It is advantageous to both the student and professor to define a few clear categories of scoring, as opposed to using multiple categories which are indecipherable and subtly different (Moskal, 2000). When grading, the student receives a score for each category and these numbers are then averaged together for a final grade. For example, the student may receive a 3 for content development, 3 for analysis, 2 for professional language, 4 for control of syntax and mechanics and 3 for sources and evidence. The average of those scores would yield a 3.0 rating, giving the student a $90 \%$. The professors use quarter increments to score when necessary (e.g. 3.25, 3.5, 3.75).

Since using this rubric (Appendix A), the authors feel that the grade is more representative of the overall quality of the student's work, and more specific feedback can be given to the students regarding the expectation of the assignment and their completed work. This feedback provides students with descriptors to facilitate improving their skills for future writing assignments, rather than just assigning a numerical value (Moskal, 2000). For example, rather than the student simply receiving an " 87 ", they are provided with a qualitative description of their work in each area by referencing the score they received (content development, analysis, use of professional language, use of syntax and mechanics and use of sources and evidence). The descriptions within the rubric should add value to the processes of self-reflection and peer response. Additionally, a strength of using a common rubric across courses is that the students learn that there are standards of expectation regardless of the instructor (Plante, 2011).

Another benefit noted by the authors was the use of the rubric in instruction. For example, when teaching about the PICO assignment, the professor added an activity where the students rate provided reports using the rubric. It is felt that by using the rubric to rate another report, the students become more aware of how to improve their own writing skills. The more familiar and confident students are with requirements for a good written report, the easier it is for the students to write comprehensive and high-quality reports. Instructors should take the time to educate students on the specific terminology used in the rubric, what is expected to receive mature and exemplary scores, and explain the terms of descriptors such as incomplete, limited and few. 
There has been no data gathered at this point due to the rubric only being recently implemented and no Institutional Review Board (IRB) procedure in place. Since there is no data to suggest that this rubric is reliable and valid, there are limitations in providing guidelines for implementation. However, the authors believe this rubric can be used as a model for grading undergraduate and graduate students in academic and clinical settings, with a goal of increasing the clarity of documentation expectations, improving the quality of present and future clinical writing, and promoting ease of instructor grading. In the future, the effectiveness of the use of the rubric should be assessed to ensure the proposed student and instructor outcomes. Students could be surveyed for their perspective on the rubric as an instructional tool.

References

Allen, M. J. (2014, March). Using rubrics to grade, assess, and improve student learning. Paper presented at Strengthening Our Roots: Quality, Opportunity \& Success Professional Development Day. Miami-Dade College, Miami, FL.

American Speech-Language-Hearing Association. (2014). 2014 Standards and Implementation Procedures for the Certificate of Clinical Competency in Speech Language Pathology. American Speech and Hearing Association. Retrieved from www.asha.org/Certification/2014-Speech-Language-Pathology-Certification-Standards/

Association of American Colleges and Universities. (2017). Current VALUE Research. Available online at: https://www.aacu.org/current-value-research

Brookhart, S. M. (2013). How to create and use rubrics for formative assessment and grading. Alexandria, VA: ASCD Publications.

Burrus, A. E., \& Willis, L. B. (2017). Professional communication in speech-language pathology: How to write, talk, and act like a clinician ( $3^{\text {rd }}$ Ed.). San Diego, CA: Plural Publishing.

Butler, K. G., \& Silliman, E. R. (2002). Speaking, reading and writing in children with language learning disabilities: New paradigms in research and practice. Mahway, NJ: Lawrence Erlbaum Associations, Inc.

Finley, A. (2011). How Reliable are the VALUE Rubrics? Association of American Colleges \& Universities. Retrieved from www.aacu.org/publicationsresearch/periodicals/how-reliable-are-value-rubrics

Grillo, E., Koenig, M., Gunter, C., \& Kim, S. (2014). Teaching CSD graduate students to think critically, apply evidence, and write professionally. Communication Disorders Quarterly, 36(4), 241-251. Retrieved from https://doi.org/10.1177/1525740114549014

Lee-Wilkerson, D. \& Chabon, S. S. (2008). Reflections on a rubric used to 
facilitate accurate and informative assessment. Perspectives on Administration and Supervision, 18, 58-66. doi:10.1044/aas18.2.58

Moskal, B. M. (2000). Scoring rubrics: What, when and how? Practical Assessment, Research \& Evaluation, 7(3), 1-5. Retrieved from http://PAREonline.net/getvn.asp? $=7 \& n=3$.

Plante, E. (2011, March). Writing skills across the disciplines. Paper presented at Council of Academic Programs in Communication Sciences and Disorders Conference, St. Pete Beach, FL.

Schneider-Cline, W. (2017). Developing graduate students' self-regulation and critical thinking during a clinical writing workshop. Teaching and Learning in Communication Sciences \& Disorders, 1(1), 1-22. 


\section{Appendix A}

The Rubric

\begin{tabular}{|c|c|c|c|c|}
\hline & 1-Beginning & 2-Developing & 3-Mature & 4-Exemplary \\
\hline $\begin{array}{l}\text { Content } \\
\text { Development }\end{array}$ & $\begin{array}{l}\text {-Does not include required } \\
\text { or relevant components } \\
\text {-Includes irrelevant } \\
\text { information } \\
\text {-Includes inaccurate } \\
\text { information }\end{array}$ & $\begin{array}{l}\text {-Includes all required or } \\
\text { relevant components } \\
\text {-A few instances of } \\
\text { irrelevant information } \\
\text {-No inaccurate } \\
\text { information }\end{array}$ & $\begin{array}{l}\text {-Includes all required or } \\
\text { relevant components|AND } \\
\text { uses content to develop and } \\
\text { explore ideas through the } \\
\text { majority of the report } \\
\text {-No instances of irrelevant } \\
\text { information } \\
\text {-Paints a basic and accurate } \\
\text { picture of the session }\end{array}$ & $\begin{array}{l}\text {-Includes all required or relevant } \\
\text { components } \\
\text { AND } \\
\text { uses content to develop and explore } \\
\text { ideas through the entire report AND } \\
\text { the report conveys the writer's } \\
\text { understanding of clients' performance } \\
\text { and needs } \\
\text { - No instances of irrelevant information } \\
\text {-Paints an accurate and whole picture of } \\
\text { the session beyond the objective data } \\
\end{array}$ \\
\hline Analysis & $\begin{array}{l}\text {-Lists data but does not } \\
\text { adequately explain OR make } \\
\text { appropriate } \\
\text { recommendations }\end{array}$ & $\begin{array}{l}\text {-Includes data and an } \\
\text { incomplete attempt of } \\
\text { analysis AND } \\
\text { recommendations }\end{array}$ & $\begin{array}{l}\text {-Synthesizes data and makes } \\
\text { a limited analysis AND } \\
\text { general recommendations }\end{array}$ & $\begin{array}{l}\text {-Synthesizes data to reveal insightful } \\
\text { patterns and makes thorough and } \\
\text { specific } \\
\text { recommendations }\end{array}$ \\
\hline $\begin{array}{l}\text { Use of } \\
\text { Professional } \\
\text { Language }\end{array}$ & $\begin{array}{l}\text {-No evidence of professional } \\
\text { language } \\
\text {-Professional terminology is } \\
\text { misused } \\
\text { or impedes the meaning } \\
\text { because of errors in usage }\end{array}$ & $\begin{array}{l}\text {-Little evidence of } \\
\text { professional language } \\
\text {-Limited and accurate } \\
\text { use of professional } \\
\text { terminology }\end{array}$ & $\begin{array}{l}\text {-Evidence of professional } \\
\text { tone and discipline-specific } \\
\text { language AND accurate use of } \\
\text { professional terminology } \\
\text { throughout the majority of } \\
\text { the report }\end{array}$ & $\begin{array}{l}\text {-Evidence of professional tone and } \\
\text { discipline-specific language AND } \\
\text { accurate use of professional terminology } \\
\text { throughout the entire report }\end{array}$ \\
\hline $\begin{array}{l}\text { Control of } \\
\text { Syntax and } \\
\text { Mechanics }\end{array}$ & $\begin{array}{l}\text {-Frequent errors in spelling } \\
\text { or grammar (e.g. misused } \\
\text { punctuation, incomplete } \\
\text { sentences, etc.) } \\
\text {-Lack of flow or organization } \\
\text { in writing } \\
\text {-Frequent tense shifts }\end{array}$ & $\begin{array}{l}\text {-Some spelling and/or } \\
\text { grammatical errors } \\
\text {-Some consideration } \\
\text { given to organization } \\
\text { but poor flow of writing }\end{array}$ & $\begin{array}{l}\text {-Very few spelling and/or } \\
\text { grammatical errors } \\
\text {-Consistent organization and } \\
\text { flow of writing }\end{array}$ & $\begin{array}{l}\text {-No spelling or grammatical errors } \\
\text {-Writing exhibits sophisticated } \\
\text { organization and flow to fluently and } \\
\text { clearly communicate thoughts }\end{array}$ \\
\hline \multicolumn{5}{|c|}{$\begin{array}{l}\text { The instructor will select the most representative classification of each category (e.g. "Content and Development", "Analysis", etc) based } \\
\text { on your report. }\end{array}$} \\
\hline $\begin{array}{l}\text { Sources and } \\
\text { Evidence }\end{array}$ & $\begin{array}{l}\text {-No appropriate AND/OR } \\
\text { credible sources used to } \\
\text { support the chosen evidence- } \\
\text { based practice }\end{array}$ & $\begin{array}{l}\text {-Demonstrates an } \\
\text { attempt to use } \\
\text { appropriate AND } \\
\text { credible sources to } \\
\text { support the chosen } \\
\text { evidence-based practice }\end{array}$ & $\begin{array}{l}\text {-Demonstrates consistent use } \\
\text { of appropriate AND credible } \\
\text { sources to support the chosen } \\
\text { evidence-based practice }\end{array}$ & $\begin{array}{l}\text {-Demonstrates skillful use of high quality } \\
\text { appropriate AND credible sources }\end{array}$ \\
\hline
\end{tabular}

